\title{
Transtorno de conduta/TDAH e aprendizagem da Matemática: um estudo de caso
}

\author{
Carolina Innocente Rodrigues \\ Maria do Carmo Sousa \\ João dos Santos Carmo
}

\section{Resumo}

O presente artigo tem por objetivo descrever um estudo de caso em relação a um aluno do Ensino Fundamental previamente diagnosticado como portador de Transtorno de Conduta (TC) associado a Transtorno de Déficit de Atenção e Hiperatividade (TDAH), com acentuadas dificuldades na aprendizagem de Matemática. Partiu-se da necessidade de uma descrição operacional do quadro e da indagação acerca da relação entre TC/ TDAH e aprendizagem da Matemática. O estudo envolveu entrevistas com direção e professora, análise documental, observação em sala de aula e interação com o aluno em situações pedagógicas. Os dados obtidos apontam que a presença de TC/TDAH não produziu as dificuldades na aprendizagem da Matemática, embora concorra para que essas dificuldades se acentuem. Fatores ligados à família e à forma como a escola lida com o caso foram determinantes na evolução do quadro. São oferecidas diretrizes e sugestões para que a escola reestruture seu trabalho junto à criança.

Palavras-chave: Transtorno de Conduta, transtorno da falta de atenção com hiperatividade, ensino da Matemática.

\section{Conduct Disorder and Attention Deficit/Hyperactivity Disorder related to mathematics learning: a case-study}

\begin{abstract}
The present article aims to describe a case-study about an elementary school pupil showing high mathematics learning difficulties and previously diagnosed with Conduct Disorder (CD) associated to Attention Deficit/Hyperactivity Disorder (ADHD). Initially an operational description of the case was devised, as well as the relation between CD/ADHD and mathematics learning. The case study involved interviews, documental analysis, classroom observations, and interaction with the pupil in pedagogical contexts. Data showed that CD/ADHD did not produced the suggested math learning difficulties, although such association, along with parental and school factors, tended to aggravate the case development. Specific directions and suggestions in order to reorganize the school actions on the case are presented.
\end{abstract}

Key-words: Conduct disorder, attention deficit disorder with hyperactivity, mathematics education.

\section{Transtorno de conducta/TDAH y aprendizaje de matemáticas: un estudio de caso}

\section{Resumen}

Este artículo tiene el objetivo de describir un estudio de caso relacionado a un alumno de Educación Primaria previamente diagnosticado como portador del Trastorno de Conducta (TC) asociado al Trastorno de Déficit de Atención e Hiperactividad (TDAH), con marcadas dificultades en el aprendizaje de Matemáticas. Se partió de la necesidad de una descripción operacional del cuadro y de la indagación a cerca de la relación entre TC/TDAH y aprendizaje de Matemáticas. El estudio comprendió entrevistas con la dirección y profesora, análisis documental, observación en aula e interacción con el alumno en situaciones pedagógicas. Los datos obtenidos indican que la presencia de TC/TDAH no produjo las dificultades en el aprendizaje de matemáticas, a pesar de que contribuye para que esas dificultades se acentúen. Factores relacionados a la familia y a la forma como la escuela trata el caso fueron determinantes en la evolución del cuadro. Se ofrecen directrices y sugerencias para que la escuela reestructure su trabajo con el niño.

Palabras-clave: Trastorno de conducta, trastorno por déficit de atención con hiperactividad, ensenanza de matemáticas. 


\section{Introdução}

Profissionais que atuam em escolas, particularmente professores e coordenadores pedagógicos, têm demonstrado crescente preocupação com o aumento de casos de transtornos psiquiátricos entre os alunos (Gequelin \& Carvalho, 2007; Poeta \& Neto, 2004; Rios, 2006). Dentre estes, temos o Transtorno de Conduta (TC), em relação ao qual parte significativa dos educadores encontra-se sem o suporte teórico e instrumental necessário para dar um encaminhamento preciso.

O TC é classificado como transtorno psiquiátrico em crianças e adolescentes, enquanto a expressão personalidade antissocial é aplicada a indivíduos com mais de 18 anos, segundo o Manual Diagnóstico e Estatístico de Transtornos Mentais (DSM-IV-TR) (APA, 1995). De acordo com este manual, o TC é um dos transtornos psiquiátricos mais frequentes na infância e um dos motivos de encaminhamento ao psiquiatra infantil. É descrito como a presença de comportamentos que perturbam e incomodam, além do envolvimento em atividades perigosas e ilegais. $\mathrm{O}$ indivíduo com este transtorno produz maior impacto nos outros que em si mesmo - não se importa em transgredir regras ou desrespeitar, fere sentimentos e não se constrange com a própria atitude (Bordin \& Offord, 2000).

Segundo o DSM-IV-TR, são 15 os critérios para diagnosticar o TC: 1) Frequentemente persegue, atormenta, ameaça ou intimida os outros; 2) Frequentemente inicia lutas corporais; 3) Já usou armas que podem causar ferimentos graves (pau, pedra, caco de vidro, faca, revólver); 4) Foi cruel com as pessoas, ferindo-as fisicamente; 5) Foi cruel com os animais, ferindo-os fisicamente; 6) Roubou ou assaltou, confrontando a vítima; 7) Submeteu alguém a atividade sexual forçada; 8) Iniciou incêndio deliberadamente com a intenção de provocar sérios danos; 9) Destruiu propriedade alheia deliberadamente (não pelo fogo); 10) Arrombou e invadiu casa, prédio ou carro; 11) Mente e engana para obter ganhos materiais ou favores ou para fugir de obrigações; 12) Furtou objetos de valor; 13) Frequentemente passa a noite fora, apesar da proibição dos pais (início antes dos 13 anos); 14) Fugiu de casa pelo menos duas vezes, passando a noite fora, enquanto morava com os pais ou pais substitutos (ou fugiu de casa uma vez, ausentando-se por um longo período); 15) Falta na escola sem motivo, matando aulas frequentemente (início antes dos 15 anos). Para que o diagnóstico se confirme, é preciso que o indivíduo apresente pelo menos três destes critérios nos últimos 12 meses e, pelo menos, um comportamento antissocial nos últimos seis meses, desde que tragam visíveis prejuízos acadêmicos, sociais ou ocupacionais.

De um ponto de vista médico, os sintomas surgem no início da infância e puberdade e, quando se iniciam antes dos 10 anos, podem surgir acompanhados do TDAH. Estudos indicam uma alta taxa de comorbidade entre TDAH, TC e transtorno opositor desafiante (30 a 50\%). No Brasil, Rohde e cols. (1999) encontraram uma relação de $47,8 \%$. Estes índices são corroborados por Pastura, Mattos e Araújo
(2007). Evidentemente que os dados advindos da área médica necessitam de contextualização a fim de não se incorrer no equívoco de considerar os transtornos como fenômenos puramente biológicos, uma vez que a história ambiental e de vida de cada indivíduo é, sem dúvida, fator preponderante (Moysés, 2001).

Segundo Farrell (2001/2008), o TDAH pode ser considerado como uma dificuldade comportamental, emocional e social - visão adotada pelo Código das Necessidades Educacionais Específicas (DfES, 2000) e podem ser diferenciados três subtipos: o TDAH com predomínio de sintomas de desatenção, o TDAH com predomínio de sintomas de hiperatividade/impulsividade e o TDAH combinado (APA, 1995).

Landskron e Sperb (2008) informam que os sintomas abrangem três categorias: desatenção (dificuldade para sustentar a atenção por períodos prolongados, seguir instruções, completar as lições e organizar tarefas; tendência a perder objetos, esquecer compromissos e distrair-se com estímulos externos); hiperatividade (agitação motora, inquietude e tendência a falar excessivamente); e impulsividade (dificuldade de aguardar sua vez e tendência de interromper os outros ou se intrometer em assuntos alheios). Fatores sociais podem prognosticar a gravidade do quadro ou a presença de comportamentos mais agressivos ou desafiadores (Barkley, 2000 citado por Landskron \& Sperb, 2008; Grillo \& Silva, 2007). O TC está associado a baixo rendimento escolar e a problemas de relacionamento com colegas, trazendo limitações acadêmicas e sociais à criança ou ao adolescente (Bordin \& Offord, 2000; Grillo \& Silva, 2004; Pitzer, Esser, Schimidt, \& Laucht, 2009), enquanto o TDAH relaciona-se às dificuldades de aprendizagem com comprometimento específico da linguagem escrita ou verbal (Rohde, Barbosa, Tramontina \& Polanczyk, 2000). Esses transtornos, associados frequentemente, produzem grande prejuízo na vida escolar da criança (Pastura e cols., 2007).

Como estratégia de intervenção em ambos os transtornos, existem diversos procedimentos que incluem intervenções junto à família e à escola, administração de medicamentos (neurolépticos e/ou psicoestimulantes), mas nenhuma intervenção se mostrou eficiente isoladamente e, quanto mais cedo o diagnóstico correto ocorrer, melhor resposta ao tratamento a criança dará. Vale ressaltar que, em quaisquer transtornos, não basta olhar para o comportamento desadaptativo. É preciso verificar se outros parâmetros estão presentes e em que medida, como: contexto em que ocorre; frequência; intensidade; duração; prejuízos significativos na vida pessoal, acadêmica e social do indivíduo (ver, p. ex., Grillo \& Silva, 2007). Desse modo, evitar-se-ão a pressa em rotular e a hipervalorização de comportamentos que, em certa medida, ocorrem dentro de parâmetros aceitáveis (Guarido, 2007; Luengo \& Constantino, 2009; Moysés, 2001).

Particularmente em relação à disciplina Matemática, é possível hipotetizar que a aprendizagem de seus conteúdos seja prejudicada em função de que a presença de TC/ TDAH associados, além das barreiras já apontadas, pode potencia- 
lizar as dificuldades de entendimento dos conteúdos devido às próprias características da disciplina e, também, devido ao fato de que muitos professores das séries iniciais não detêm um domínio considerado "adequado" dos conteúdos matemáticos, uma vez que tiveram pouca ou praticamente nenhuma formação em Matemática. Desse modo, conforme tem sido enfatizado, não se trata de limitar a análise à uma visão biologizante dos transtornos, o que levaria a uma culpabilização do indivíduo ou da família, mas sim de enfatizar que os indivíduos são produtos de relações sociais/culturais mais amplas, envolvendo não só padrões familiares, mas toda uma cultura e discurso em torno da Matemática como sendo algo de difícil apreensão (Correa \& MacLean, 1999), bem como práticas pedagógicas que nem sempre garantem a elaboração de conteúdos significativos aos alunos.

Em relação aos conteúdos de Matemática, exige-se dos alunos uma grande capacidade de atenção, seguimento de regras (algoritmos) e estabelecimento de relações entre eventos, habilidades que possivelmente são difíceis de serem apresentadas com regularidade em casos de TC/TDAH, dadas as características descritivas desses transtornos. O desconhecimento dos transtornos e a falta de estratégias adotadas pela escola para lidar e oferecer o encaminhamento correto têm gerado uma série de equívocos de avaliação que, muito comumente, fazem recair sobre o aluno o rótulo de portador de Dificuldade de Aprendizagem (DA). Este é um termo extremamente vago e amplo que tem servido, no máximo, para excluir os indivíduos do acesso a condições minimamente adequadas de ensino, bem como tem sido usado pela escola para isentá-la da responsabilidade em lidar com o caso (Costa, 1993; Moysés, 2001; Moysés \& Collares, 1992; Patto, 1990).

Diante da insegurança e desamparo em que se encontram professores e outros agentes educacionais, quando se trata de lidar com situações específicas de TC e TDAH, por exemplo, o diagnóstico médico e a própria medicalização são buscados como forma de lidar com as dificuldades de aprendizagem (e de ensino) daí advindas. Desse modo,

A esperança fica depositada no medicamento, que vai adaptar o aluno à escola, ou nas instâncias superiores do sistema de ensino, que vão prover a escola de recursos materiais e pedagógicos para que esta se adapte à criança que se distingue do esperado (Landskron \& Sperb, 2008, p. 164).

Segundo Pacheco (2005), revela-se assim um processo de produção de estigmatização de crianças, no qual o diagnóstico de DA pode estar sendo confundido com problemas relacionados à disciplina do aluno em classe, à sua adaptação social à sala de aula ou às expectativas do professor em relação ao comportamento ideal do estudante.

Seria interessante que o professor conversasse com colegas de crianças com DA ou TDAH para refletir sobre preconceitos construídos, crenças e medos, de forma que sejam afastados com esclarecimento e não imposição (Landskron \& Sperb, 2008; Rohde \& Halpern, 2004; Rohde e cols., 2000). A escola não pode simplesmente querer enquadrar os alunos e exigir um comportamento disciplinado, sem antes adaptar seu currículo e linguagem à realidade de sua clientela (Pacheco, 2005; Rohde e cols., 2000).

Paiano e cols. (2007) apontam que algumas características de famílias podem ser fatores de risco aos transtornos de conduta: histórico de transtorno mental e práticas educativas inapropriadas (p. ex., bater e humilhar). Por outro lado, Gequelin \& Carvalho (2007) destacam que pais e professores podem ser modelos significativos no oferecimento e manutenção de regras consistentes no ambiente escolar. Rios (2006) acrescenta que é possível desenvolver programas de intervenção precoce junto a famílias com o objetivo de prevenir o surgimento de problemas de conduta em préescolares. Para tanto, propõe um programa educativo para pais que visa ao desenvolvimento de condutas pró-sociais e à diminuição de práticas educativas coercitivas (abuso físico e psicológico; negligência; disciplina relaxada; punição inconsistente e monitoria negativa).

As digressões até aqui apontadas chamam atenção para o fato de que a escola ainda não recebeu um suporte adequado que a auxilie a identificar transtornos comprometedores do desempenho escolar e social de seus alunos, e a desenvolver estratégias de apoio a esses alunos. Por outro lado, é imperiosa a condução de estudos que possam destacar as possíveis relações entre esses transtornos, isolados ou em associação, e os desempenhos em conteúdos específicos. Esses desempenhos podem ser afetados pelos transtornos apresentados? Em que medida? Que procedimentos podem ser tomados pela escola e professores diante de quadros como o aqui apresentado? Pautado nessas questões, o presente estudo relata a condução de um estudo de caso envolvendo um aluno do Ensino Fundamental com diagnóstico informado pela escola de TC/TDAH. Ao término do estudo, verificou-se em que medida os transtornos associados interferiam no desempenho em Matemática e indicou-se, como sugestão, a conduta a ser tomada pela escola diante do caso.

\section{Método}

Participante: uma criança do sexo masculino (doravante chamada de VN), de nove anos de idade, diagnosticada com TC associado a TDAH. À época do estudo, VN frequentava o $5^{\circ}$ Ano do Ensino Fundamental - ciclo II (antiga $4^{\text {a }}$ série) de uma escola privada na cidade de São Carlos/ $\mathrm{SP}$.

Estratégias de coleta de informações: 1) Entrevistas com a administradora escolar que era coordenadora da escola quando VN entrou para o $1^{\circ}$ ano do Ensino Fundamental e com a professora de VN; 2) Análise documental a partir da consulta à dissertação de mestrado de uma professora da escola que tratava, dentre outros assuntos, de como foi o processo de adaptação da escola (diretores, coordenadores, professoras, alunos) em relação ao comportamento de VN; 3) Observação participativa da interação professora-aluno 
Quadro 1. Síntese descritiva do caso VN

\begin{tabular}{|c|c|}
\hline $\begin{array}{l}\text { Setores- } \\
\text { chave }\end{array}$ & VN \\
\hline Saúde & $\begin{array}{l}\text { Em 2005, iniciou o tratamento com neurolépticos e psicoestimulantes; o diagnóstico } \\
\text { de TC/TDAH associados foi feito por uma neurologista. Segue tratamento com equipe } \\
\text { multidisciplinar (neurologista, fonoaudióloga, psicólogo, oftalmologista). Também } \\
\text { foi diagnosticada deficiência visual (baixa visão). Atualmente, a medicação não é } \\
\text { consumida constantemente e isto tem agravado a falta de concentração e agitação, } \\
\text { percebidas em sala de aula. }\end{array}$ \\
\hline Família & $\begin{array}{l}\text { Família com relação conturbada, a mãe de VN tem um filho mais velho, do primeiro } \\
\text { casamento, que tem alguma deficiência desconhecida pela escola em que VN estuda, } \\
\text { pois a mãe não trata do assunto. Sabe-se apenas que é um adolescente, estuda } \\
\text { na APAE e mora com a avó materna de VN; segundo a diretora da escola, a mãe } \\
\text { teve depressão durante a infância de VN quando percebeu que seu filho não era } \\
\text { tido como "normal". Os pais de VN são separados, o pai tem namorada. Durante o } \\
\text { ano de } 2005 \text {, quando VN entrou na escola, identificou-se que sofria agressões por } \\
\text { parte da mãe; esta situação foi discutida pela professora, coordenadora e diretora da } \\
\text { escola e posteriormente com os pais, mas pouco foi modificado em decorrência desta } \\
\text { conversa. A escola, após diversas advertências, acionou o Conselho Tutelar e este, } \\
\text { por sua vez, no terceiro chamado, passou a guarda de VN provisoriamente para o pai. } \\
\text { Mesmo sofrendo agressões, VN não desenvolveu sentimentos ruins pela mãe e ela, } \\
\text { segundo relato da professora de VN, usa este aspecto para fazer jogos de chantagem } \\
\text { com o objetivo de se reconciliar com o ex-marido. Um exemplo destas chantagens é } \\
\text { em relação à medicação de VN: as receitas estão com a mãe que não as entrega ao } \\
\text { pai, a não ser que volte a morar com ela. }\end{array}$ \\
\hline Escola & $\begin{array}{l}\text { Teve papel fundamental no diagnóstico de VN, por orientar constantemente os pais } \\
\text { que procurassem ajuda médica e psicológica a fim de detectar os problemas que VN } \\
\text { estava enfrentando; foi na escola que houve a identificação de características de TC, } \\
\text { como agressividade, intimidação em relação aos colegas e alterações de humor. }\end{array}$ \\
\hline $\begin{array}{l}\text { Relações } \\
\text { sociais }\end{array}$ & $\begin{array}{l}\text { Alterna momentos de agressividade e carinho por alguns colegas e pela primeira } \\
\text { professora de VN. Teve dificuldades em respeitar os limites impostos pela então } \\
\text { coordenadora da escola. A mãe é figura importante, pois, apesar das agressões } \\
\text { infligidas por esta, demonstra carinho pela mãe. VN repetiu atitudes da mãe com } \\
\text { algumas colegas, neste caso o sexo oposto mostrou-se um fator importante, pois a } \\
\text { atenção que a mãe despendia (agressões) foi entendida como positiva por VN, já que } \\
\text { conseguia algo da mãe, então usou da mesma estratégia para conseguir obediência } \\
\text { alheia, no caso das colegas de escola. }\end{array}$ \\
\hline $\begin{array}{l}\text { Aprendiza- } \\
\text { gem }\end{array}$ & $\begin{array}{l}\text { Apresenta ritmo mais lento de aprendizagem se comparado aos colegas; tem sérios } \\
\text { obstáculos em relação à escrita nas atividades desenvolvidas em sala de aula, } \\
\text { decorrente principalmente do TDAH; contudo, em atividades que envolvem raciocínio } \\
\text { lógico, VN as desenvolve bem, mas escreve as respostas que não são corretas como } \\
\text { respostas definitivas. VN evita situações em que precisa ler. }\end{array}$ \\
\hline
\end{tabular}

em contexto de sala de aula; 4) Interação da primeira autora (à época, aluna do último semestre de licenciatura em Matemática) com VN durante as aulas de Matemática.

\section{Resultados e Discussão}

O quadro 1 apresenta a descrição do caso $\mathrm{VN}$ a partir das informações colhidas por meio das diferentes estratégias. A descrição foi dividida por setores-chave na vida de VN: saúde; família; escola; relações sociais; aprendizagem.
Ao elaborarmos uma análise mais aprofundada dos dados coletados, entendemos que fica pouco esclarecida a questão da aprendizagem de VN, pois, nas entrevistas com a diretora e com a professora, evidenciou-se que VN não tem as mesmas condições de aprendizagem que os demais alunos da turma e, portanto, não deveria estar cursando efetivamente $\circ 5^{\circ}$ ano do Ensino Fundamental.

Por outro lado, a dissertação da professora descreve que $\mathrm{VN}$ tem um atraso de 2,5 anos em relação ao que seria típico para sua idade cronológica, mas esta informação não foi citada pela diretora durante a entrevista, embora, ao que parece, as decisões pedagógicas tenham sido tomadas em relação às turmas de $\mathrm{VN}$, com base no pressuposto de sua idade mental: 
Este aluno tem a idade mental de 4,5 anos, logo os seus comportamentos são normais. Foi conversando com mãe, ela não quer tirá-lo da escola, então eu tenho que trabalhar com ele. Assim, agora que eu já sei o que ele tem, estou preparando atividades de 4 anos para ele, você precisa ver como ele melhorou. (professora de VN)

A primeira autora, na sequência, questiona se foi detectado o nível mental dele ou se foi feito algum teste. A professora de $\mathrm{VN}$ responde:

$\mathrm{O}$ pai me disse que para o $\mathrm{V}$ sentar e engatinhar ele precisou ir à fisioterapeuta, pois até os 6 meses não fixava a cabeça, começou a andar com 3 anos e a falar frases coerentes no ano passado. Então foi daí que a coordenadora concluiu que ele tinha uns 2,5 anos de atraso no desenvolvimento. Em relação à idade mental não foi feito nenhum teste, o pai me disse que a médica falou que ele é normal e que não há nada de errado. Agora estou sem saber o que fazer, porque, se ele não tem nada de errado, porque está tudo normal, agora se ele é normal, por que não teve um desenvolvimento como os outros?

Sobre o desenvolvimento de VN, a professora emitiu a seguinte informação:

Como tinha estudado na graduação a disciplina sobre o desenvolvimento da criança e do adolescente, encontrei o livro que caracteriza o desenvolvimento por idades, o diagnóstico de $V$ era de 4,5 anos, passei então a buscar na literatura algo que pudesse me ajudar a entender o processo de desenvolvimento de crianças nesta idade.

Outro fator de destaque é que, durante as observações participativas, percebeu-se uma resistência de VN em escrever, independente da atividade; porém, nos simulados de matemática realizados às sextas-feiras, por duas vezes foi percebido VN verbalizando seu raciocínio lógico corretamente, mas ao assinalar a alternativa que seria a mais correta, escolhia a incorreta. Em outro momento de interação, conduzido pela primeira autora, realizou-se acompanhamento individual com VN. O exercício envolvia a operação de adição; VN verbalizou seu raciocínio corretamente, fez os cálculos mentalmente, mas se recusou a escrever e, quando questionado sobre o motivo da recusa, respondeu que "é muito chato". Após insistência da pesquisadora, VN acabou escrevendo, mas no campo de resolução fez outros cálculos que não correspondiam ao exercício. Na formalização das operações, VN representava, por exemplo, a operação 54 + 8 da seguinte forma:

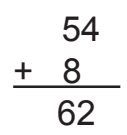

Como se vê, apesar de representar inadequadamente, o resultado final estava correto. Mas no mesmo espaço de resolução havia operações cujos resultados não estavam corretos; por exemplo:

\begin{tabular}{c}
54 \\
$+\quad 8$ \\
\hline 134
\end{tabular}

Os dados levam à suspeita de que é possível que VN ainda não tivesse adquirido a noção de sistema posicional até aquele momento. $\mathrm{O}$ caso aqui apresentado se reveste de alta complexidade e abrange diferentes áreas da vida de $\mathrm{VN}$, o que exige uma intervenção multi e interdisciplinar. A seguir, traçamos alguns indicativos e sugestões de intervenção que podem ser implementados ou apoiados pela escola.

\section{Proposta de ações gerais ao se detectar transtornos graves de conduta em sala de aula e em outros ambientes da escola:}

1 Identificar três aspectos básicos e inter-relacionados: contexto-comportamento-consequência. É muito comum que comportamentos inusitados chamem a atenção das pessoas que os observam. Agredir fisicamente, chamar palavrão, desobedecer etc. são comportamentos que costumam provocar mudanças significativas no ambiente de sala ou na escola e, por isso, é comum que haja uma espécie de sobrevalorização dos mesmos. Em outras palavras, passam a ter certo destaque, o que pode levar os alunos que se comportam fora dos padrões esperados a se tornarem o centro das atenções. Por isso, faz-se necessário primeiramente identificar o contexto em que tais comportamentos ocorrem, ou seja, em que ambientes ocorrem (sala de aula; quando a professora está ausente; quando a professora está anotando algo no quadro; quando os alunos estão trabalhando em pequenos grupos etc.). Esta primeira constatação dará indicativos seguros acerca dos contextos específicos em que determinados comportamentos ocorrem.

2 Olhar para o comportamento propriamente dito e tentar responder o mais precisamente possível as seguintes perguntas: com que frequência ele ocorre? (frequência aqui é entendida como a ocorrência do comportamento dentro de um determinado intervalo de tempo, por exemplo, uma aula de 50 minutos); com que intensidade ocorre? (por exemplo, ao dizer que um aluno costuma "bater" nos colegas, bater pode significar desde um pequeno empurrão até um soco desferido fortemente); qual a forma do comportamento? (ou seja, devemos procurar descrever como o comportamento se apresenta. Assim, se dizemos que o aluno ameaça seus colegas, devemos dizer como se dá tal ameaça. Por exemplo, ficar de pé em frente ao colega, pegar um objeto e direcionar esse objeto em direção ao colega dizendo que irá bater com o objeto caso o colega não faça o que o agressor está pedindo).

3 Identificar as consequências imediatas dos atos praticados. Por exemplo, se, ao ameaçar os colegas, o aluno consegue o que queria, provavelmente a estratégia de 
ameaçar estará sendo "premiada" e, portanto, se repetirá frequentemente. Dessa forma, é importantíssimo identificar o que ocorre imediatamente após um determinado comportamento considerado inaceitável. Às vezes, até o silêncio da professora pode ser um "prêmio" para o aluno ou mesmo retirar o aluno da sala pode ser, para ele, algo vantajoso. A atenção recebida é um fator fundamental para a perpetuação das ações, mesmo que esta atenção seja "negativa". Um pai, por exemplo, que sempre está distante do filho, mas que se aproxima dele unicamente nos momentos em que considera que o filho faz algo "errado" e grita com ele, pode, sem querer, premiá-lo com sua atenção e o filho pode aprender que agindo "mal" consegue a atenção do pai.

Assim, um primeiro conjunto de ações é observar, registrar e descrever contextos, ações e consequências a fim de se ter uma espécie de mapeamento. Isso nos dará condições de verificar, inclusive, se determinadas consequências para o comportamento estão mantendo o comportamento, ao invés de eliminá-lo.

4 Coletar impressões gerais de outros professores e dos demais agentes educacionais (porteiros, copeiras, coordenador etc.). O objetivo é ampliar o mapeamento descrito anteriormente, comparar informações e levantar hipóteses iniciais que expliquem os comportamentos estudados.

5 Promover reuniões entre coordenação e professores a fim de traçar metas: Este momento é fundamental para se tomar decisões importantes, tendo em vista que a principal meta é auxiliar o aluno. Diversas medidas podem e devem ser tomadas a depender de cada caso. Dentre as comumente implementadas, estão: 1. Convocar os responsáveis pelo aluno para um encontro no qual será exposta a situação-problema. Os pais e responsáveis devem se sentir acolhidos pela escola e nunca devem se sentir acusados, pois tal sentimento geraria uma barreira de comunicação e um provável afastamento. Importa, pois, estabelecer um vínculo positivo, respeitoso e acolhedor. Podemos encontrar pais que negarão ou não aceitarão a existência de qualquer problema no filho; podemos, também, encontrar pais que se surpreenderão com as informações; enfim, são variadas as reações. O fundamental é que a escola lembre que é sempre muito delicado ouvir a respeito de comportamentos negativos dos próprios filhos. O momento, portanto, é de acolhimento e não de acusação, é de parceria e não de disputas. É uma excelente oportunidade de colher informações fundamentais, que poderão ajudar a esclarecer o caso e a tomar medidas mais acertadas. Podemos, por exemplo, identificar aspectos relevantes do clima emocional da família e ou de episódios relevantes que podem estar diretamente relacionados ao caso.

6 Buscar o assessoramento de profissionais, conforme o caso: Psicólogos, fonoaudiólogos, neurologistas, pediatras, psiquiatras etc. são profissionais comumente requisitados em casos específicos como o aqui relatado. Os itens apresentados na síntese descritiva do Quadro 1 podem servir como modelo e como fonte de informação para o diálogo com os profissionais. Quanto mais completo o quadro- resumo, tanto melhor. É um quadro que deve ser revisitado constantemente, ampliando e ou atualizando informações.

\section{Atitudes gerais da escola}

É fundamental que os diversos agentes educacionais, na escola, entrem em acordo acerca de como proceder em cada caso. Quais medidas deverão ser tomadas, como, quando e por quem será o aluno encaminhado a setores extra-sala de aula etc, são decisões que devem ser tomadas em conjunto e devem estar muito claras. Mas, sobretudo, devem ser seguidas por todos a fim de que o ambiente educacional apresente-se coerente. Todas as medidas devem ser educativas e, de preferência, sob a orientação de profissionais que lidam com o caso. Nesse âmbito, é fundamental que a escola não tome para si a responsabilidade de solucionar o caso. Notemos que se o caso tratar-se de um simples problema disciplinar em sala de aula, evidentemente a escola, os professores são responsáveis pela situação. Mas, no caso de problemas graves, como o transtorno de conduta, TDAH, dentre outros, não cabe à escola tão somente a responsabilidade. Ela deve ser coadjuvante no atendimento ao aluno, ou seja, deve ser mais um setor envolvido no esforço de ajudar o indivíduo em sofrimento.

\section{Atenção aos professores}

Ter, em sala de aula, um aluno com graves problemas emocionais ou com deficiências, não é uma situação tranquila para o professor. Frequentemente este irá se sentir desamparado, perdido ou angustiado, sem saber como agir ou agindo de forma a agravar ainda mais o problema, mesmo sem o querer. É comum, em casos como o apresentado no presente estudo, que professores desenvolvam defesas, tornem-se amedrontados, estressados, pois se sentem impotentes para lidar com a situação. A escola precisa olhar com muito carinho e atenção para professores que têm alunos especiais. É preciso ouvi-los em suas angústias e oferecer orientação e assessoramento adequado. Não é o professor o maior responsável e sim a escola como um todo. O professor, porém, por estar na linha de frente, acaba sendo requisitado mais e, em torno dele, são geradas altas expectativas que ele, comumente, não está preparado para satisfazer. Cabe à escola buscar assessoria de profissionais que possam orientar o professor acerca do que e de como fazer diante de situações delicadas como alunos com TDAH e transtorno de conduta.

Feitas essas considerações gerais, que podem ser aplicadas a diversos casos, passamos às sugestões específicas relacionadas ao caso $\mathrm{VN}$.

Reavaliação do quadro e atendimento especializado. Em função do quadro informado de transtorno de conduta associado a TDAH, sugere-se que VN seja submetido 
a novas avaliações psiquiátrica e neurológica. Os distúrbios em geral podem sofrer alterações em intensidade e manifestação; além disso, novas avaliações afastariam qualquer suspeita de erro no diagnóstico. Por outro lado, os novos pareceres e impressões diagnósticas poderão confirmar ou alterar as prescrições de medicamentos. Ressalta-se que, confirmada a impressão diagnóstica, os responsáveis deverão ser esclarecidos quanto à manutenção do tratamento, através de visitas periódicas ao psiquiatra e uso adequado do receituário.

Atendimento psicoterápico. Sugere-se que VN seja acompanhado por psicólogo em processo de psicoterapia e que esta seja estendida a seus responsáveis e adultos que convivem diariamente em casa. A sugestão deve-se ao fato de que, através da psicoterapia, VN poderá beneficiar-se quanto a, pelo menos, três aspectos fundamentais: 1. Autocontrole e diminuição da ansiedade; 2. Reorganização de atividades de vida diária, estabelecimento e seguimento de rotinas; 3 . Desenvolvimento de estratégias adequadas de enfrentamento de situações ansiogênicas, com ampliação de repertórios de assertividade em substituição à agressividade. Por outro lado, os responsáveis em casa poderão se beneficiar através do aumento de conscientização e engajamento na busca de padrões de conduta em casa que sejam coerentes e estáveis, além de aprenderem estratégias de manejo de estresse, muito comum em familiares de pacientes com transtorno de conduta e hiperatividade.

Aproximação família-escola. Sugere-se que os responsáveis por VN sejam convidados a encontros periódicos na escola; inicialmente, encontros quinzenais, em seguida, encontros mensais e, finalmente, encontros a cada três meses. Tais encontros visam ao estreitamento de laços entre escola e família, à atualização de informações, a acordos de cooperação quanto às medidas a serem adotadas etc. Os encontros devem ocorrer, preferencialmente, entre coordenação, professor e responsáveis. Sugere-se que os encontros sejam registrados em caderno próprio. Espera-se que a presença dos responsáveis na escola possa ter, como efeito em VN, a percepção de que é querido e de que escola e família estão do mesmo lado e, portanto, tornam-se referências importantes em sua vida.

Estabelecimento de rede de relações escola-família-profissionais especializados. Sugere-se que a escola mantenha um diálogo constante com os profissionais que acompanham VN a fim de dirimirem dúvidas acerca das condutas a serem tomadas em caso de recidiva ou agravamento da situação. Igualmente é importante que esse diálogo seja estendido aos pais. Quanto mais coerentes e em acordo forem as iniciativas, tanto mais eficazes as ações.

Estabelecimento de normas específicas de conduta dentro de escola. Por ser um ambiente educacional no qual VN está inserido diariamente, sugere-se que a escola desenvolva estratégias adequadas de conduta nas diversas situações vivenciadas por VN: sala de aula, quadra de esportes, pátio da recreação, horário de intervalo, entrada e saída, biblioteca etc. Em termos práticos, isso significa que todos estarão engajados no cumprimento de normas e tais normas não devem ser quebradas ou alteradas sem a expressa discussão prévia e permissão do grupo de educadores. Regras são a especificação de três componentes básicos: se...então...caso contrário. Ou seja, na hora do lanche se VN age ordeiramente respeitando os colegas, então receberá elogios e poderá ter acesso a jogos, caso contrário, receberá advertência verbal e não participará da recreação. Note que este é apenas um exemplo hipotético, cabendo à escola estabelecer as regras de acordo com a realidade percebida. Todos devem ser informados das regras, inclusive os pais, e todos deverão cumpri-las. Dessa forma, o ambiente social escolar apresentará uma estabilidade necessária ao estabelecimento de rotinas apropriadas ao crescimento pessoal de VN.

O ambiente de sala de aula. É na sala de aula que estão as maiores manifestações de preocupação dos professores, uma vez que os comportamentos usuais de VN tipicamente atrapalham o desenvolvimento da programação didática. Sugere-se que alguns cuidados sejam tomados:

1. Estabelecer claramente para todos os alunos quais as normas vigentes em sala de aula para diversas situações (levantar, permanecer sentado, sair de sala etc.). Cumprir estas normas (se...então...caso contrário) com regularidade. Freire (1986) afirma que não devemos, enquanto educadores, ter receio de dizer não nas situações em que o não se faz necessário. VN, pelas observações feitas em sala de aula, consegue seguir regras, porém quebra as regras ou cria regras próprias em seu benefício em função, provavelmente, da falta de regularidade no cumprimento de regras estabelecidas em sala de aula.

2. Elogiar imediatamente as condutas apropriadas. Isso mostrará a VN o quanto a professora está atenta a sua conduta e o quanto condutas adequadas são valorizadas.

3. Proporcionar a VN o trabalho com crianças tranquilas que sirvam de modelo.

4. Agir assertivamente e apresentar filmes nos quais os personagens apresentam comportamentos não agressivos e maneiras adequadas de resolver problemas e conflitos.

5. Planejar momentos de brincadeiras e jogos de cooperação em sala de aula.

6. Condutas pedagógicas. As condutas a seguir, baseadas em Carmo (2010), são sugestões de manuseio de atividades que podem proporcionar maior concentração, cooperação e engajamento por parte de VN. São sugestões gerais que devem ser adequadas pelo professor conforme as necessidades: permitir o uso de calculadora e tabela de tabuada; uso de caderno quadriculado; nas provas, elaborar questões claras e diretas; reduzir 
ao mínimo o número de questões; fazer prova sozinho, sem limite de tempo e com um tutor para certificar se entendeu o que pedem as questões; permitir que o aluno possa fazer prova oralmente, desenvolvendo as expressões mentalmente, e ditando para que alguém as transcreva; moderar a quantidade de lição de casa; passar exercícios repetitivos e cumulativos; incentivar a visualização do problema, com desenhos e depois internamente; prestar atenção ao processo utilizado pela criança - que tipo de pensamento VN usa para resolver um problema?; fazer uma aula "livre de erros" para esse aluno conhecer o sucesso; evitar dar muitas ordens ao mesmo tempo (por exemplo, "abra o livro de história na página 39, faça agora os exercícios 1, 2 e 3 no caderno e faça os exercícios 4 e 5 em casa numa folha de monobloco para ser entregue até $4^{a}$ feira"); nomear monitores, colegas de classe que podem ajudar; dar dicas, atalhos e jeitos de fazer associações que ajudem a lembrar dos pontos da matéria (prompts); evitar rotulá-los; permitir o uso de gravador para determinados momentos da aula; iniciar a aula com um resumo da aula anterior; anotar no quadro o tema e os objetivos a serem atingidos na aula; anotar no quadro os passos e procedimentos a serem seguidos; fazer uma síntese ao final da aula; dar feedback imediato para cada tarefa realizada; trabalhar por aproximações sucessivas, valorizando tentativas; incentivar o uso de estratégias de memorização e recuperação de informações; promover momentos de revisão periodicamente; partir do simples para o complexo, do que está próximo para o que está distante, do que já sabe para o que falta aprender; proporcionar atividades de generalização da aprendizagem; estimular os canais sensoriais de entrada; tomar cuidado no uso de regras e crenças inadequadas; usar a história da Matemática e dos conceitos matemáticos como recurso didático; diversificar os materiais, experiências e atividades (jogos, construções de modelos, gincanas, filmes etc).

\section{Considerações finais}

Neste artigo, investigamos possíveis relações entre TC/TDAH e aprendizagem da Matemática. Para tanto, realizou-se um estudo de caso, no qual foram aprofundados aspectos relevantes da vida de um aluno que apresentava, segundo informações dadas pela escola, a associação daqueles trantornos. Embora VN apresentasse padrões de comportamento que fazem parte de TC e, também, de TDAH, o diagnóstico preciso nunca foi apresentado pela escola. Identificamos que o caso VN extrapolava a sala de aula e se enraizava em conturbadas relações familiares, o que refletia em seu desempenho escolar (ver Quadro 1).

Particularmente em relação à Matemática, percebemos que VN apresentava algumas dificuldades específicas, descritas ao longo do estudo de caso (ver Quadro 1); porém tais dificuldades não são necessariamente geradas por TC ou pelo TDAH, embora esses quadros sejam determinantes de certos comportamentos que podem dificultar a apreensão de conteúdos. Desse modo, os autores sugerem que, no caso estudado, não havia relação direta entre TC/TDAH e as dificuldades em Matemática apresentadas pelo aluno.

O presente estudo não teve como foco apontar erros da família ou da escola, mas sim entender como o entrelaçamento de relações, dentro e fora da escola, foi determinante na produção das dificuldades apresentadas pelo aluno. Outro fator que deve ser ressaltado é que a escola onde VN estuda esteve aberta para nos apoiar com informações importantíssimas sobre o caso, mostrando que, cada vez mais, a Universidade deve estar atenta ao movimento escolar e a escola deve receber suporte da Universidade por meio de estudos e projetos científicos.

\section{Referências}

Associação Americana de Psiquiatria (APA). (1995). Manual Diagnóstico e Estatístico de Transtornos Mentais. (C. Dornelles, Trad.) (4 ed.). Porto Alegre: ArtMed.

Bordin, I. A. S., \& Offord, D. R. (2000). Transtorno de conduta e comportamento anti-social. Revista Brasileira de Psiquiatria, 22, Supl. II: 12-15.

Carmo, J. S. (2010). Fundamentos psicológicos da educação. Curitiba: Ibpex.

Correa, J., \& MacLean, M. (1999). Era uma vez... um vilão chamado matemática: um estudo intercultural da dificuldade atribuída à matemática. Psicologia: reflexão e crítica, 12, 173-194.

Costa, D. A. F. (1993). Fracasso escolar: diferença ou deficiência?. Porto Alegre: Kuarup.

Farrell, M. (2008). Dislexia e outras dificuldades de aprendizagem específicas: guia do professor (M. A. V. Veronese, Trad.). Porto Alegre: Artmed. (Trabalho original publicado em 2001)

Freire, P. (1986). Paulo Freire e os educadores de rua: uma abordagem crítica. Brasília: Unicef/ Funabem.

Gequelin, J. \& Carvalho, M. C. N. (2007). Escola e comportamento anti-social. Ciências \& Cognição, 11, 132-142.

Grillo, E., \& Silva, R. J. M. (2004). Manifestações precoces dos transtornos do comportamento na criança e no adolescente. Jornal de Pediatria, 80(2), S21-S27.

Guarido, R. (2007). A medicalização do sofrimento psíquico: considerações sobre o discurso psiquiátrico e seus efeitos na educação. Educação e Pesquisa, 33, 151-161.

Landskron, L. M. F., \& Sperb, T. M. (2008). Narrativas de professoras sobre o TDAH: um estudo de caso coletivo. Revista Psicologia 
Escolar e Educacional, 12(1), 153-167.

Luengo, F. C., \& Constatino, E. P. (2009). Avigilância punitiva: a postura dos educadores no processo de patologização e medicalização da infância. Revista de Psicologia da Unesp, 8, 122-126.

Moysés, M. A. A. (2001). A institucionalização invisível: crianças que não aprendem na escola. Campinas, SP: Mercado das Letras.

Moysés, M. A. A., \& Collares, C. A. L. (1992). A história não contada dos distúrbios de aprendizagem. Cadernos CEDES, 28, 31-48.

Pacheco, L. M. B. (2005). Diagnóstico de dificuldade de aprendizagem?! Temas em Psicologia, 13(1), 45-51.

Paiano, M., Andrade, B. B., Cazzoni, E., Araújo, J. J., Waidman, M. A. P., \& Marcom, S. S. (2007). Distúrbios de conduta em crianças do ensino fundamental e sua relação com a estrutura familiar. Revista Brasileira de Crescimento e Desenvolvimento Humano, 17, 111121.

Pastura, G., Mattos, P. \& Araújo, A. P. Q. C. (2007). Arquivos de Neuropsiatria, 65(4-A), 1078-1083.

Patto, M. H. S. (1990). A produção do fracasso escolar: histórias de submissão e rebeldia. São Paulo: T A Queiroz.

Poeta, L. S., \& Neto, F. R. (2004). Estudo epidemiológico dos sintomas do déficit de atenção/hiperatividade e transtornos de comportamento em escolares da rede pública de Florianópolis usando a EDAH. Revista Brasileira de Psiquiatria, 23, 150-155.
Pitzer, M., Esser, G, Schimidt, M. H., \& Laucht, M. (2009). Early predictions of antisocial developmental pathways among boys and girls. Acta Psychiatrica Scandinavica, 121, 52-64.

Rios, K. S. A. (2006). Efeitos de um programa de prevenção de problemas de comportamento em crianças pré-escolares de famílias de baixa renda. Dissertação de Mestrado, Universidade Federal de São Carlos, São Carlos-SP.

Rohde, L. A., Barbosa, G., Tramontina, S., \& Polanczyk, G. (2000). Transtorno de déficit de atenção/hiperatividade. Revista Brasileira de Psiquiatria, 22(Supl. II): 7-11.

Rohde, L. A., Biederman, J, Busnello, EA, Zimmermann, H, Schmitz, M e cols. (1999). ADHD in a school sample of brazilian adolescents: a study of prevalence, comorbid conditions, and impairments. Journal of the American Academy of Child and Adolescent Psychiatry, 38(6), 716-722.

Rohde, L. A. \& Halpern, R. (2004). Transtorno de déficit de atenção/ hiperatividade: atualização. Jornal de Pediatria, 80(2 Supl), S61-S70.

Rossini, S. D. R., \& Santos, A. A. A. (2001). Fracasso escolar: estudo documental de encaminhamentos. Em F. F. Sisto., E. Boruchovitch \& L. D. T. Fini (Orgs.), Dificuldades de aprendizagem no contexto psicopedagógico (pp. 214-235). Petrópolis, RJ: Vozes.

\section{Sobre os autores}

Carolina Innocente Rodrigues (carol.innocente@uol.com.br)

Universidade Federal de São Carlos, São Paulo - SP.

Maria do Carmo Sousa (mdcsousa@ufscar.br) carmojs@gmail.com; Universidade Federal de São Carlos, São Carlos - SP

João dos Santos Carmo (carmojs@gmail.com)

Universidade Federal de São Carlos, São Carlos - SP

Instituto Nacional de Ciências e Tecnologia sobre Comportamento, Cognição e Ensino (1)

\section{Correspondência}

Carolina Innocente Rodrigues

Rua Francisco de Oliveira Penteado, 148 - Boa Vista - CEP: 13574-310. São Carlos/SP

\section{Agradecimentos}

Apoio do CNPq e FAPESP. 